\title{
AN EXPLORATION OF FLOW DURING INTERNET USE
}

\section{Ruth Rettie ${ }^{1}$}

\section{Senior Lecturer Kingston University}

Ruth Rettie is a Senior Lecturer in marketing at Kingston University in the U.K. Teaching and research interests include Internet Marketing and International Marketing. Prior to joining Kingston University in 1990, she spent 10 years as a Brand Manager for Unilever.

\footnotetext{
${ }^{1}$ R.Rettie@Kingston.ac.uk 


\title{
AN EXPLORATION OF FLOW DURING INTERNET USE
}

\begin{abstract}
Several authors have suggested that the concept of flow is useful for understanding consumer behavior in computer mediated environments, (Csikszentmihalyi, 1990; Trevino and Webster, 1992; Hoffman and Novak, 1996).

Previous Internet flow research has used self-completion questionnaires. This research uses focus groups to facilitate the identification and discussion of respondents' Internet experience. The research explored respondents' awareness and experience of flow. Half of the respondents recognized Internet flow experience.

Internet flow seems to prolong Internet and web site usage. Several factors that promote or inhibit Internet flow were identified. These factors may help practitioners design web sites that stimulate flow and encourage users to stay on the site.
\end{abstract}

\section{Keywords}

Consumer Behavior

Internet

E-commerce

Flow

Web site design 


\section{AN EXPLORATION OF FLOW DURING INTERNET USE}

\section{Conceptual Framework}

Csikszentmihalyi $(1975, \mathrm{p} 36)$ introduced the concept of flow, which he defined as "the holistic experience that people feel when they act with total involvement". When in the flowstate, people are absorbed in an activity, their focus of awareness is narrowed, they lose selfconsciousness, and they feel in control of their environment. Studies report flow experience in numerous activities including rock climbing, dancing, chess, reading, etc (Csikszentmihalyi 1975; Csikszentmihalyi and LeFevre 1989). Several authors have suggested that the concept of flow is useful for understanding consumer behavior in computer mediated environments, (Csikszentmihalyi, 1990; Trevino and Webster, 1992, Ghani and Deshpande 1994).

Internet flow is described here by a respondent in this research "If I really get into something then, you know, I suddenly look at my watch and it's like two hours later and I don't know where the time has gone, but that's from just concentrating so much that you don't really know what's going on around you. My colleague actually said that I needed to go for a hearing test but it's not because I can't, I'm just completely transfixed."

Hoffman and Novak (1996) identify flow as a key characteristic of consumer behaviour on the Internet, "flow is the 'glue' holding the consumer in the hypermedia Computer Mediated Environment." (page 57). Hoffman and Novak also apply the concept to repeat usage, (1997, page 51), "Research can determine the variables that relate to a consumer's propensity to enter the flow-state, and such information can be used to develop marketing efforts....since repeat visits to a particular web site will be increased if the environment facilitates the flow- 
state." Commercially, the concept of 'stickiness' is a crucial element of web design; this includes features like regularly updated content and online diaries which increase the frequency and duration of web site visits; design which encourages flow should increase stickiness, but not all 'stickiness' is due to flow. This paper explores the nature of the experience of flow and the factors that inhibit and promote it.

Csikszentmihalyi (1975) originally identified four flow components: control, attention, curiosity, and intrinsic interest. These were replaced, Csikszentmihalyi (1993, p178 -179), with eight dimensions of the flow experience: clear goals and immediate feedback; equilibrium between the level of challenge and personal skill; merging of action and awareness; focused concentration; sense of potential control; loss of self-consciousness; altered sense of time, and experience becoming autotelic or self-rewarding. See Table I for an explanation and Internet examples of these dimensions. Csikszentmihalyi saw the balance between perceived challenge and personal skill as a necessary condition of flow. Where the level of skill is below the perceived challenge a person is in a state of anxiety, where skill exceeds challenge he is bored; only where they match he is in flow.

"Take in Table I"

There are two methodological problems with empirical research of flow, the nature of the concept and the timing of the research. Flow is not a concept familiar to respondents, therefore in order to research it one either has to teach respondents the concept, or one has to use scales of related constructs. The latter is unsatisfactory because if flow is a distinct, holistic experience it cannot be operationalized in terms of other states or experiences, in the same way that one cannot ascribe happiness on the basis of a smile. This research adopts the 
approach that in order to identify and illuminate the experience of flow the concept itself needs to be discussed with respondents. The timing problem is that if there is a delay between the experience of flow and the interrogation of the respondent there is a loss of information through memory decay, on the other hand respondents are irritated if interrupted and questioned while in the flow-state.

Conventional flow research has adopted two main methodologies, the flow questionnaire, which explains the concept and asks respondents to describe similar previous experiences, and the Experience Sampling Method or ESM (Larson and Csikszentmihalyi, 1983), which interrupts respondents at random intervals.

The flow questionnaire (Csikszentmihalyi, 1982; Delle Fave, A and Massimini, F, 1988) contains three standard descriptions of flow derived from Csikszentmihalyi's earlier research, (see Figure 1). The three quotations, which are also used in this research, are:

1. “My mind isn't wandering. I am not thinking of something else. I am totally involved in what I am doing. My body feels good. I don't seem to hear anything. The world seems to be cut off from me. I am less aware of myself and my problems."

2. "My concentration is like breathing. I never think of it. I am really oblivious to my surroundings after I really get going. I think that the phone could ring, and the doorbell could ring, or the house burn down or something like that. When I start, I really do shut out the whole world. Once I stop, I can let it back in again."

3. "I am so involved in what I am doing, I don't see myself as separate from what I am doing.”

"Take in Figure 1." 
In the flow questionnaire respondents were presented (in a self-completion questionnaire) with the three descriptions and asked whether they could recall similar experiences of their own. They were then asked to describe these experiences, and to rate associated experiences, e.g. level of involvement, effort, anxiety, etc. This methodology depends on respondents recognizing the flow descriptions and relating them to their own previous experiences.

ESM, or the Experience Sampling Method (Larson and Csikszentmihalyi, 1983), was designed to remove the time delay between the experience of flow and the research. Respondents were given a diary and a pager for a week. They were paged about 8 times a day on a random (daytime) basis. When paged they were asked to complete a page of the diary relating to their current experience at that time. This method asks respondents to report their feelings "on the spot", and does not rely on their memory of past experiences. More radically, flow is not self diagnosed but defined in terms of the balance of challenges and skills. Respondents were asked to rate the challenges of the activity and their skills in the activity, usually on a 10-point scale. In early research 'flow' was defined as occurring when challenge and skill levels matched.

This methodology was refined because flow did not show the predicted relationships. Massimini and Carli (1988) suggested that flow only begins where skills and challenge are matched and above a certain level, and they consequently defined 'flow' as occurring when challenges and skills are matched and above the individual's mean for these scales. They modified the original three-channel model, suggesting a four-channel model of apathy, anxiety, boredom, and flow. 
Chen, Wigand and Nilan (1998) integrated the ESM technique with digital auto-ask technology to create a new on-line ESM technique. A special computer program was created and installed on the respondent's computer. When the subject was using the Internet, a questionnaire popped up at random intervals. On each occasion, respondents were asked to complete numerical scales relating to their Internet experience immediately before the questionnaire appeared. As in the standard ESM research methodology, respondents were not asked directly about flow. The research sample was 100 individuals from a university. Using 11-point Likert scales, flow was defined in terms of the level and match of challenge and skill. However, some results from this research were contradictory to flow theory, for instance, those defined as in the flow-state were less likely to have clear goals, less likely to concentrate on Web pages, and obtained less enjoyment from their navigation.

On-line ESM collects Internet users' subjective experiences contemporaneously, and does not rely on their retrospective recollections. However, respondents found the technique invasive, and were reluctant to complete the questionnaire more than three times, (the traditional pager/diary ESM collected over 20 questionnaires from each respondent), this means that unless flow occurs very frequently the questionnaire is unlikely to appear during the flow experience. It is also likely that when engrossed and in flow, subjects find the pop-up questionnaire particularly annoying, which may explain the contrary results. The technique could be adapted to site-exit popup questionnaires, to reduce interruption. However, the question remains as to whether flow should be measured indirectly, as here with equilibrium of skill and challenge above a prescribed level, or directly, which would involve teaching respondents the concept of flow before commencing the research. 
Chen, Wigand, and Nilan, (1999a, page 592) argue that a descriptive approach allows users to describe their flow experiences in their own terms, and provides "a key to understanding the relationship between activities of Web users and the processes by which an individual reaches a harmonious state in his/her consciousness (i.e., flow)". In an "attempt to generate some basic description of the flow phenomenon" (page 584), they used the flow questionnaire quotations in a survey of 304 respondents, using open-ended questions to categorize the flow experience. Respondents were shown the three standard descriptions of flow. Respondents who had experienced flow on the Internet, (40\% of respondents), were then asked to describe their last Internet flow experience. Using content analysis of the openended questions they found that $20 \%$ to $40 \%$ of students could not understand Csikszentmihalyi's flow concepts of 'challenge' and 'sense of control'.

Ghandi and Deshpande (1994) developed a model in work-related computer use, using scales to measure items for enjoyment ('flow'), concentration, perceived control and perceived challenge. Novak et al (1999) adopted a structural modeling approach to conceptualize flow. Their model is derived from an Internet survey of over 2000 heavy users, and uses 10 constructs from the literature and a web usage variable. However, all their questions related to the general experience of Internet use, which conflicts with Csikszentmihalyi's situation specific use of the flow concept. That is, people were not asked about a particular experience, but asked about their general experience. Their answers, therefore, refer not to a particular state but to their Internet experience as a whole. Thus a correlation between, for example, focussed attention and flow, does not mean that the experiences are related, just that those who experience one are likely to experience the other (but not necessarily at the same time). From this one cannot deduce anything about the experience of flow itself. This paper also used two new descriptions of flow, and these may have affected the correlations 
identified, for example, flow is defined in terms of time distortion - ' time may seem to stand still', (Novak et al, 1999)

Nel, Berthon and Davies (1999) found correlation between flow score and different categories of web site, using the web site typology of Quelch and Klein (1996). In their experiment the 36 student respondents (including 10 who were new to the Internet) were asked to evaluate 20 specified web sites, and complete a questionnaire after evaluating each site. They completed 5 point Likert scales for the original four flow components: control, attention, curiosity and intrinsic interest, using scales derived from Webster et al. (1993). The different scales are simply added together to produce a measure for the flow experience although this 'flow' scale has not been correlated with the flow experience of respondents. Their research assumes that all subjects (including novices) experienced flow (albeit to different degrees) at 20 different sites in a single computer session. This use of 'flow' differs markedly from the totally engrossing experience described by Csikszentmihalyi and others.

Research in numerous non-Internet contexts found about $87 \%$ of American adults report the experience of flow (Csikszentmihalyi 1993, page 199). Using the same questionnaire for the Internet, Chen et al (1999a) found approximately $40 \%$ recognized the flow experience, while Novak et al (1999) found 47\% recognized their description of flow.

\section{Methodology}

The objective of this research was to find out whether users actually experience flow on the Internet, to understand the nature of the experience using the framework of Csikszentmihalyi's eight dimensions of flow, and to identify factors that inhibit or promote flow on the internet. 
Previous research on Internet flow has either used other constructs to define the experience of flow or self-completion questionnaires. The former is not satisfactory, if flow is a holistic experience it cannot be identified on the basis of different, albeit related, feelings. Selfcompletion questionnaires assume respondents can understand the flow concept and related constructs, and do not allow respondents to clarify concepts with the interviewer and each other. The interactivity of focus groups resolves this problem. This research therefore uses the flow questionnaire descriptions, but uses focus groups rather than self-completion questionnaires. Focus groups also capture respondents' descriptions of the Internet experience before the flow concept is introduced, and allow the separate introduction of the three flow descriptions, enabling respondents to discuss each description individually.

Focus groups were also used because this method facilitates the identification and interrogation of internal experience. "Because moderators can challenge and probe for the most truthful responses, supporters claim qualitative research can yield a more in-depth analysis than that produced by formal quantitative methods.”, (Mariampolski, 1988, page 21). Groups are not intimidating for respondents, and shared experiences 'spark off' others, (Gordon and Langmaid, 1988). Focus groups “....can be especially useful for topics where people are not in touch with or able to articulate their motivations, feelings and opinions", or where "researchers wish to understand (behaviors) that are not a matter of conscious importance in everyday life", (Morgan, 1998 page 58).

Four $1 \frac{1}{2}$-hour focus groups were held; the 32 respondents all used the Internet at least five hours per week, and had been using the Internet for at least two years. The single sex groups 
consisted of $18-25$ males, 18 - 25 females, $25-35$ females, and $35-50$ males. The researcher, who is an experienced moderator, led the groups.

After a general discussion of Internet usage and attitudes focussing on the role of the Internet and its perceived advantages and disadvantages, respondents were shown a concept board containing Flow Description One (see Figure 2). Respondents were asked whether they had had similar experiences in any context, and then whether this had occurred during Internet use. Subsequently they were shown Flow Descriptions Two and Three; each time discussion was focussed first on their flow experience in general, and then on their Internet experience. The word 'flow' was not used; they were asked about 'similar experiences to those described on the board'.

"Take in Figure 2."

The research explored respondents' awareness and experience of 'flow', the factors that promote or inhibit it, and the nature of the experience. In addition to discussion of flow experience in general, respondents were asked to describe specific experiences. The groups were recorded; the tapes were transcribed and analyzed in terms of the common themes emerging from the groups.

\section{Main Findings}

20 respondents had Internet access at home and at work, 6 only at home and 6 only at work. All respondents used the Internet for at least 5-10 hours a week. The older male group was more experienced; that is, they had used the Internet for longer, used it for more hours per week, and were more likely to have access in both locations. 


\section{Internet uses}

Main home uses were research for holidays and travel, e-mail, educational research, downloading software, job seeking, entertainment and chat rooms. Other uses included finding out what's going on, following hobbies or sports, downloading music, booking flights, holidays and tickets. E-mail was popular with all respondents for its speed, informality, ease of use, low cost and 24 hour availability.

\section{Spontaneous Flow Experience}

In three groups there were spontaneous descriptions of flow on the Internet during the introductory discussion.

"You can completely ignore the phone ringing, people walking past. You can be so intent on what you're doing." Younger male

"You're on a high aren't you?"

Older female

Flow Description One was introduced first. Respondents were first asked whether they had had this experience at all, in any situation (i.e. not necessarily on the Internet). All groups and most respondents recognized this description of flow experience and applied it to flow activities such as reading and sport. The older female group immediately related it to their Internet use; younger male and females were slower but nearly all felt that they had experienced flow on the Internet. The group of older men found it more difficult to identify with flow in general, and could not relate it to their Internet experience at all. Overall 16 of the 32 respondents had experienced flow on the Internet. 
While respondents strongly identified with the description, they challenged the "My body feels good" aspect which is clearly more relevant to physical activity, "The brain feels good, not your body."

Flow Description Two was then introduced, followed by Flow Description Three. There was much less identification with these descriptions. Respondents tended to be very literal and felt they were too extreme or "over the top". The third description they felt related more to physical activities.

Respondents described many different Internet flow experiences. Flow can occur in all types of Internet use, searching for information, communicating with e-mail or in chat rooms, transacting or browsing for entertainment. However, respondents felt it was more likely to occur when searching for information. This is in line with Chen et al (1999a) who found that $66 \%$ of reported flow occurred during 'generic Web activities' such as research and information retrieval.

\section{Factors which Inhibit flow}

Factors that inhibit flow were of three types; the nature of the experience, concerns about Internet use and the respondent.

“When you're sort of waiting for something to download that's when I'm likely to think 'Oh, what am I going to get for dinner' or look at the time then." Younger female

Slow downloads were likely to disrupt flow. Respondents became bored and lost their concentration. Other factors were frustrating sites which they couldn't figure out (this corresponds to a mismatch between their skill and challenge level, which creates anxiety), 
failures in navigation, unsuccessful searches and advertising banners. These factors decrease involvement, and also reduce perceived control. Boring sites, and sites, which rarely change, also inhibited flow.

Respondents were extremely negative about advertising, which they found particularly irritating when in flow, as in these quotations:

“Annoying. (I) Just completely ignore them. You just immediately know, that's adverts, get rid of it."

"You do get these ones flashing up which you're not interested in and it's like 'Get out of my face' sort of thing."

Internet flow is less likely at work when use is illicit, as they need to be prepared for interruptions and cannot allow themselves to become too involved. Respondents were concerned about the costs and opportunity costs of Internet use. They know that they can lose awareness of time when experiencing flow, and have developed tactics to prevent it because of cost, or other commitments. Worries about call charges and Internet connection charges discouraged prolonged use. They also felt guilty about neglecting their families and about monopolizing the telephone line, when there is only one.

\section{Conditions which facilitate flow}

Respondents felt that flow was more likely when they were actively involved (e.g. selecting options, communicating) and getting immediate responses. Interactivity holds their attention and creates the feeling of control. Flow is more likely to occur when they have a specific task than when they are just surfing for fun. In use for entertainment there was less concentration and more likelihood of distraction.

\section{Czikszentmihalyi’s Eight Flow Dimensions}


Each of the eight dimensions was discussed in the groups, although respondents sometimes found it difficult to understand or relate to these concepts.

\section{Clear Goals and Immediate Feedback}

'It depends how interactive the site is though doesn't it, really? I mean if it's just a standard text site then that really is exactly the same as a magazine, you just scroll down the page and that's all the happens, but if there are a lot of interactive things to do on it then it's a lot more, well stimulating really."

Older female

All felt flow is more likely when carrying out a specific task, such as searching for information, because it is more engrossing. When they were just browsing or surfing for entertainment there was less concentration and more likelihood of distraction; they felt they were less involved, and less likely to experience the total absorption typical of flow. Respondents felt that immediate feedback was necessary for flow to occur. Internet delays, such as long download times or the need to acquire plug-ins to view sites, disrupted the flow experience.

\section{Equilibrium Between the Level of Challenge and Personal Skill}

"Maybe when you start using it, it is a bit of a challenge because you're not used to it."

Younger male

The group that identified most readily with Internet flow, the older female respondents, saw the Internet as a challenge, which they welcomed. The younger respondents did not identify with the concept of challenge, which they saw as stressful and irritating. For many the Internet had been a challenge when they first started, but was no longer a challenging. 
Some are excited and proud of their Internet skills, others more blasé. Internet success does not depend purely on skill, "I think lucky is more, more than skilful”. In Csikszentmihalyi's work, skill is usually conceived (and measured) as a continuum, with different skill levels. However, many spoke as if Internet skills are more like learning to drive or to ride a bicycle, and not a linear scale.

\section{Merging of Action and Awareness}

Most saw their Internet use as inactive, and therefore did not feel there was a merging of action and awareness. But for some, the action of typing became automatic when in flow.

"You are typing it in and you are like being a part of it." Older female

\section{Focused Concentration}

"You're in-depth in it, engrossed." Older male All agreed that the Internet flow involved focussed attention. Attention was more focussed in goal directed activity (e.g. information seeking) than in entertainment use. Focussed attention was enhanced by interactivity, and broken by download delays.

\section{Sense of Potential Control}

“It keeps your attention because it's your decision where you're going to go next, it's up to you what path you take."

Younger female

"You'd like to be more in control you can't tell what's going to come up when you click on something”

Younger male 
A sense of control sustains their attention, and therefore facilitates flow. There is some feeling of control because they make choices and interactivity allows them to control their navigation. This is limited by the unpredictability of their navigation. They also worry about privacy and about what is being downloaded onto their machines (e.g. cookies). When they feel out of control, flow is interrupted and they are tempted to log off.

\section{Loss of Self-consciousness}

Most respondents did not relate to this. They generally experienced flow when they used the Internet at home, and when they were alone; they were unlikely to feel self-conscious under these conditions.

\section{Time Distortion}

"You can just spend hours and hours without really realizing." Younger male

“You're quite focussed on what you're doing... you do become completely involved, that's probably when you tend to lose track of time the most." Younger female

Nearly all have had this experience, and loss of up to two hours is common; one mother forgot to collect her children from school. To respondents this was clearly the most significant effect of flow, but they were ambivalent about it. On the one hand it reflected their enjoyment, but they feel they need to fight it because of the cost, or conflicting commitments. The time distortion effect demonstrates the way that flow acts like a 'glue' keeping users on the Internet, and at a web site.

\section{Autotelic or Self-rewarding Experience}


"You can get a sense of satisfaction out of it I think when you have been absorbed in something.", but I think it's only afterwards you think “Oh goody.” Because you're absorbed in the actual thing you're not really thinking about how you're feeling."

Younger female

Respondents clearly enjoy using the Internet. However, they were not aware of Internet flow as a rewarding experience at the time, rather they deduced it was from the way they lost track of time and their state of arousal: "I mean you are buzzing when you've finished", (older female). Arousal was reported in all groups; after flow they felt refreshed, awake.

\section{Discussion of the Findings}

Half the respondents had experienced flow on the Internet, close to the $40 \%$ found by Chen et al, (1999a) and the 47\% reported by Novak and Hoffman, (1999). This is much lower than Csikszentmihalyi's figure of $87 \%$ for experiencing flow in any activity. Many respondents had experienced flow in other activities but not on the Internet, some thought this was because the Internet only involved one sense, others felt inhibited by the work environment. Respondents' spontaneous use of the concept before its introduction, and its connection with time distortion and therefore with extent of use, supports 'flow' as an important concept in understanding Internet behaviour.

The older men did not identify with Internet flow; this could be because they had been using the Internet for longer, and therefore they found the challenge they faced was below the threshold of their skills i.e. boredom in the three channel model. Novak et al (1999, p.38) found that "the degree to which the online experience is compelling appears to decrease with years of experience online". 
Respondents identified most with the first of the three standard quotations; this seems to be most applicable to flow on the Internet. In future research this could be used on its own, without the words 'My body feels good' which are less appropriate.

Many factors currently inhibit Internet flow. Downloading time is the most important, exacerbated by web sites using anima tics and large picture files. Utilization of the telephone line, use of the Internet at work, and usage costs are other inhibitors. However, in the future, faster connection lines, increased home penetration and falling costs should all facilitate Internet flow. Multitasking, using other computer activities simultaneously such as instant messenger, work processing, and several browser windows is increasing. This could increase flow, as surfers avoid delays by seamlessly moving between applications, alternatively it could reduce concentration and interrupt flow.

Advertising can hinder or disturb flow, particularly flashing interstitials, which take time to download and interrupt concentration. Recent research by Schlosser et al, (1999) has found that Internet advertising generates considerable irritation. Jenner (2000) found that $66 \%$ of respondents had left a web site because of the advertising. Drèze and Hussherr (1999) found that surfers purposely avoid looking at banner ads, this may be to avoid interrupting the flow experience. It may be that when in the enjoyable flow-state, surfers are particularly negative if interrupted by advertising. Thus encouraging flow at a web site might prolong usage of that site, but adversely effect response to advertising on the site.

While respondents recognized most of Csikszentmihalyi's dimensions, the merging of action and awareness and loss of self-consciousness were not really relevant in the computer mediated environment. For them immediate response was the key antecedent, and time 
distortion the most noticeable characteristic of flow. It may be possible to design a practical 'flow quotient' for web sites based on just these two criteria. Designing sites with increased interactivity should promote flow, and perceived time lapsed may confirm its occurrence. Commercially, extended use is the objective, and time distortion may be the crucial factor. See Table II for suggestions for designing web sites for flow.

"Take in Table II."

\section{Research limitations}

This research was exploratory and involved a quota sample of only 32 respondents who may not be representative of the Internet population. The moderator can bias focus groups and as the moderator was the researcher, this may have influenced the findings. The flow concept was introduced using descriptions of flow, these will have influenced respondents' understanding of flow.

Focus groups were chosen because respondents do not understand the concept of flow and therefore cannot answer questions until they have learned the concept. Groups help respondents to understand and identify their feelings, and thus can elicit a better response than questionnaires. The dynamics of focus groups enabled the introduction of the flow descriptions in a way that did not presume that respondents had had this experience, and allowed them to describe their own experiences

However, recall accuracy decreases with time and respondents were discussing flow in an environment both physically and temporally distant from their experience, a limitation which also effects traditional flow questionnaire research. ESM and on-line ESM minimise this 
problem, but introduce a conceptual problem by measuring flow indirectly in terms of skill and challenge.

\section{Future research}

Further quantitative research is needed to confirm that flow increases both Internet usage in general, and 'stickiness' at a specific website. The inhibitors/facilitators identified here could be tested in further quantitative research. The following hypotheses arise from this work:

$\mathrm{H}_{1}$ The duration of an Internet session is correlated with the occurrence of Internet flow during that session.

$\mathrm{H}_{2}$ The 'stickiness' or frequency of usage, duration, and browsing depth (number of pages visited) of a web site is correlated with the occurrence of flow at that site.

$\mathrm{H}_{3}$ Internet flow at a web site is correlated with users' ability to control the site. This could be measured in terms of perceived control, ease of navigation, degree of site personalization, etc.

$\mathrm{H}_{4}$ Internet flow at a web site is correlated with the interactivity of the site. This could be measured in terms of interactive features such as search engines, games, links, instant messenger, chat, email response.

$\mathrm{H}_{5}$ Internet flow at a web site is inversely correlated with response to advertising at that site.

$\mathrm{H}_{6}$ Internet flow is correlated with communication connection speed.

$\mathrm{H}_{7}$ Internet flow is inversely correlated with length of Internet experience.

\section{Conclusions}

Internet flow is relevant to consumer behaviour on the Internet. Currently about half of Internet users experience flow. These users enjoy this experience, and it increases the time 
they spend on the Internet through time distortion. Flow is a difficult concept to measure; for practical web design it may be possible to measure the time distortion effect instead.

Internet flow is constrained by several factors. Technological development will reduce these inhibitors; in the meantime web site designers can promote flow by minimizing download file sizes, improving site navigation, avoiding spurious links and maximizing both interactivity and user control of web sites. Perversely while flow may retain surfers at a web site where they are subject to advertising, it may adversely affect their response to that advertising.

\section{References}

Chen, H., Wigand, R. T., and Nilan, M. (1998), "Optimal flow experience in web navigation", Effective Utilization and Management of Emerging Information Technologies, 9th Information Resources Management Association International Conference, Idea Group Publishing, Boston.

Chen, H., Wigand R.T. and. Nilan, M (1999a), "Flow Experiences on the Web", Computers in Human Behavior, Vol. 15 No. 5, pp. $454-608$.

Csikszentmihalyi, M. (1975), Beyond Boredom and Anxiety, Josey-Bass, San Francisco. Csikszentmihlayi, M. (1982), “Towards a Psychology of Optimal Experience”, in Wheeler, L. (Ed.), Annual Review of Psychology and Social Psychology, Vol. 3, Sage, Beverly Hills, pp. $13-36$.

Csikszentmihalyi, M. (1990), Flow: The Psychology of Optimal Experience, Harper and Row, New York.

Csikszentmihalyi, M. (1993), The Evolving Self: A Psychology for the Third Millennium. HaperCollins Publishers Inc., New York.

Csikszentmihalyi, M. and. LeFevre, J. (1989), “Optimal Experience in Work and Leisure”, Journal of Personality and Social Psychology, Vol. 56 No. 5, pp. 815-822.

Delle Fave, A. and Massimini, F. (1988), "The Changing Contexts of Flow in Work and Leisure", in Csikszentmihalyi, M. and I.S. Csikszentmihalyi (Eds.), Optimal Experience: Psychological Studies of Flow in Consciousness, Cambridge University Press, Cambridge, pp. 193-213.

Drèze, X. and F.Hussherr, 1999. Internet advertising: Is anybody watching? Working Paper, Marshall School of Business, University of Southern California. Available http://sbaxdm.usc.edu/Publications/eye.html

Hoffman, D. L., and Novak, T.P. (1996), "Marketing in Hypermedia Computer-Mediated Environments: Conceptual Foundations", Journal of Marketing, Vol. 60, pp. 50-68.

Hoffman, D., and Novak, T. P. (1997), "A new marketing paradigm for electronic commerce", The Information Society: Special Issue on Electronic Commerce, Vol. 13, pp.4354.

Ghani, J.A. and Deshpande S.P. (1994), "Task characteristics and the experience of optimal flow in human-computer interaction", Journal of Psychology, Vol 128 No 4, pp. 381 - 391. Gordon W. and Langmaid, R. (1988), Qualitative Market Research, Gower, Aldershot. 
Han, S. (1988), "The Relationship between Life Satisfaction and Flow in Elderly Korean Immigrants", in Csikszentmihalyi, M. and I.S. Csikszentmihalyi (Eds.), Optimal Experience: Psychological Studies of Flow in Consciousness, Cambridge University Press, Cambridge, pp. 138-149.

Jenner, B., (2000), “Can Internet advertising lead to user alienation”, Unpublished Kingston University dissertation.

Larson, R. and Csikszentmihalyi, M. (1983), “The Experience Sampling Method", in Reis, H.T. (Ed.) Naturalistic Approaches to Studying Social Interaction: New Directions of methodology in Social and Behavioral Science, Vol. 15, Josey-Bass, San Francisco.

Mariampolski, H. (1984), “The resurgence of qualitative research”, Public Relations Journal, Vol. 40 No.7, pp. $21-23$.

Massimini, F and Carli, M. (1988), "The Systematic Assessment of Flow in Daily

Experience", in Csikszentmihalyi, M. and I.S. Csikszentmihalyi (Eds.), Optimal Experience: Psychological Studies of Flow in Consciousness, Cambridge University Press, Cambridge, pp. 266 - 288.

Morgan, D.L. (1998), The Focus Group Guidebook, in D.L. Morgan and R.A. Krueger, The Focus Group Kit, Sage Publications, California.

Nel V., D.N.R., Berthon, J. and Davies T. (1999), "Going with the flow: web sites and customer involvement", Internet Research, Vol. 9 No. 2.

Novak, T.P., Hoffman, D.L., and Yung Y.F. (1999), "Measuring the customer experience in online environments: A structural modeling approach", Marketing Science, Vol. 19, No. 1, pp. $22-42$.

Quelch, J. A. and Klein, L.R. (1996), “The Internet and International Marketing”, Sloan Management Review, Spring, pp.60-74.

Schlosser, A.E., Shavitt, S. and Kanfer, A. (1999), "Survey of Internet users attitudes toward Internet advertising", Journal of Interactive Marketing, Vol 13. No. 3, pp. $34-55$.

Trevino, L.K. and Webster, J. (1992), "Flow in computer-mediated communication", Communication Research, Vol. 19 No. 5, pp. 539-573.

Webster, J., Trevino, L.K. and Ryan, L. (1993), "The dimensionality and correlates of flow in human-computer interactions", Computers in Human Behavior, Vol. 9, pp. 411-26. 
$\underline{\text { Table I Csikszentmihalyi's Dimensions of Flow (Csikszentmihalyi 1993, pp 178 -179) }}$

\begin{tabular}{|c|c|c|}
\hline Dimension & Explanation & Internet Example \\
\hline \multicolumn{3}{|l|}{ Antecedents } \\
\hline $\begin{array}{l}\text { Clear Goals } \\
\text { Immediate feedback }\end{array}$ & $\begin{array}{l}\text { Defined task } \\
\text { Quick response }\end{array}$ & $\begin{array}{l}\text { Search for information } \\
\text { Browser responds quickly }\end{array}$ \\
\hline $\begin{array}{l}\text { Skills/challenge matched and } \\
\text { relatively high }\end{array}$ & $\begin{array}{l}\text { Opportunities to act balanced } \\
\text { by ability }\end{array}$ & $\begin{array}{l}\text { Web skills adequate for } \\
\text { navigation choices }\end{array}$ \\
\hline \multicolumn{3}{|l|}{ Characteristics } \\
\hline $\begin{array}{l}\text { Merging of action and } \\
\text { awareness }\end{array}$ & $\begin{array}{l}\text { Distinction between action } \\
\text { and actor disappears }\end{array}$ & $\begin{array}{l}\text { Become unaware of typing, } \\
\text { or moving mouse }\end{array}$ \\
\hline Focused concentration & Total focus on the present & Oblivious to interruptions \\
\hline Sense of potential control & Feel in charge of situation & Feel in control of navigation \\
\hline Loss of self-consciousness & $\begin{array}{l}\text { Stop worrying about } \\
\text { appearances }\end{array}$ & $\begin{array}{l}\text { Forget the people around one } \\
\text { at work }\end{array}$ \\
\hline Time distortion & Altered sense of time & Surf for much longer \\
\hline Autotelic experience & Self rewarding & Enjoy surfing experience \\
\hline
\end{tabular}

\section{Table II Web Design for Flow}

\begin{tabular}{|l|l|}
\hline Features that inhibit/interrupt flow & Features that encourage Flow \\
\hline Long download time & Quick download time \\
\hline Delays to download plug-ins & Alternative versions \\
\hline Long registration forms & Auto completion of forms \\
\hline Limited stimulation, boring sites & Opportunities for interaction \\
\hline Slow responses & Rapid responses \\
\hline Sites which are not intuitive & Navigation which creates choices \\
\hline Navigation links that fail & Predictable navigation for control \\
\hline Challenge greater than skill & Segment by internet experience \\
\hline Irrelevant advertising & Use of memory extension concepts \\
\hline
\end{tabular}

\footnotetext{
${ }^{2}$ A memory extension concept like a bookmark enables a surfer to avoid interrupting flow. The company Coovi. at www.coovi.com has developed a system that enables surfers to clip advertisements and promotions and respond later.
} 


\section{Figure 1 Extract from a Flow Questionnaire}

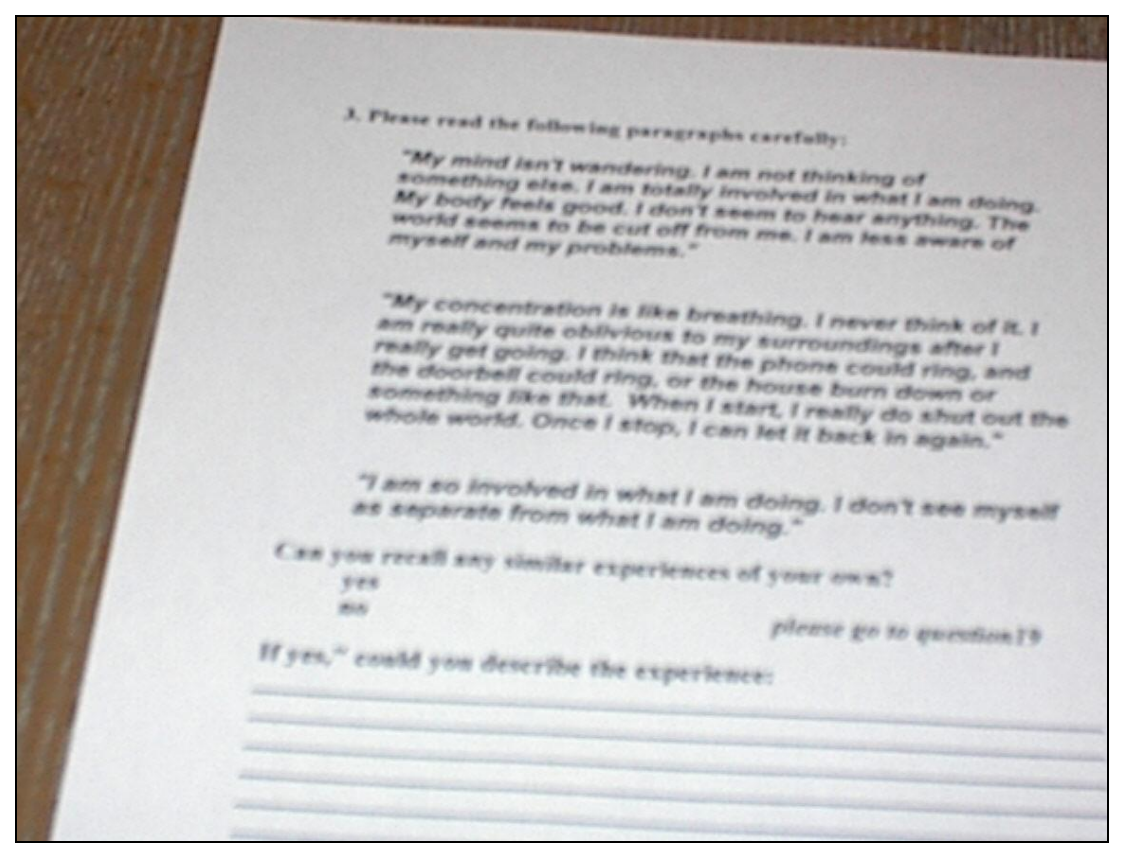

\section{Figure 2 Flow Description Concept Boards}

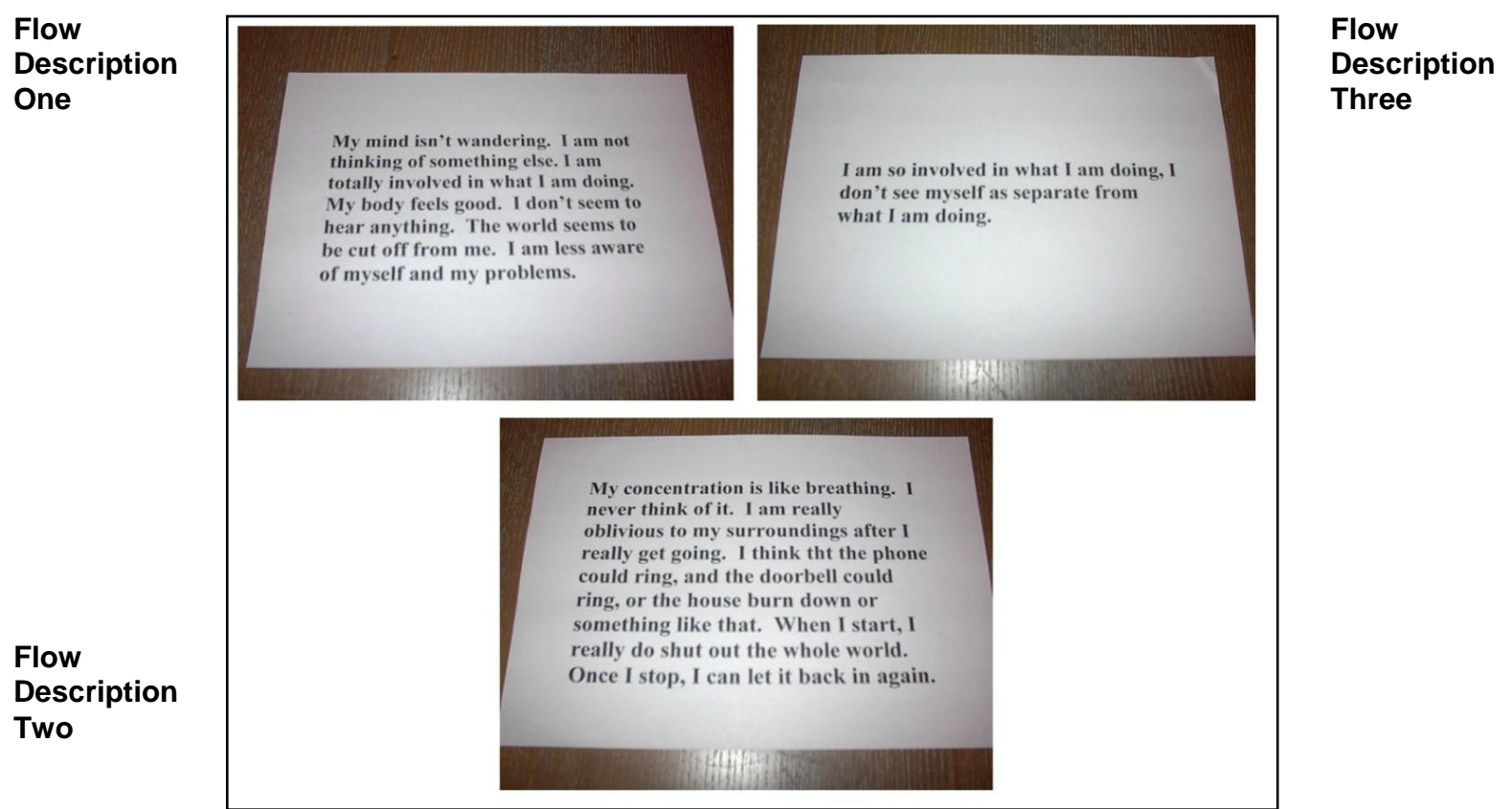


